Supporting information

\title{
Natural and Sustainable Superhydrophobic Nanochitin Aerogels for Collecting Methane Bubbles from Underwater
}

Junfei $\mathrm{Xu}^{* \mathrm{a}}$, Yuliang Zhang ${ }^{\mathrm{a}}$, Jizhong $\mathrm{He}^{\mathrm{a}}$, Jun $\mathrm{Wu}^{\mathrm{a}}$, Weiqi Li ${ }^{\mathrm{a}}$, Hailong Zhang ${ }^{\mathrm{a}}$, Haiwen Wang ${ }^{\mathrm{b}}$ Jiajia Tu ${ }^{\mathrm{a}}$, Yin Zhou ${ }^{\mathrm{a}}$, Yunyuan Dong ${ }^{\mathrm{c}}$ and Dongdong Zhu ${ }^{{ }^{\mathrm{a}}}$

${ }^{\mathrm{a} K e y ~ l a b o r a t o r y}$ of Air-driven Equipment of Zhejiang Province, College of Mechanical Engineering, Quzhou University, Quzhou 324000, China

${ }^{\mathrm{b} C o l l e g e}$ of Teacher Education, Quzhou University, Quzhou 324000, China

${ }^{\mathrm{c} C o l l e g e}$ of Chemical \& Materials Engineering, Quzhou University, Quzhou 324000, China

*Corresponding authors.

E-mail addresses: feijunxu@,126.com (J.Xu)

E-mail addresses: zhudd8@163.com (D. Zhu)

Number of pages: 3

Number of figures: 2

Number of tables: 0 


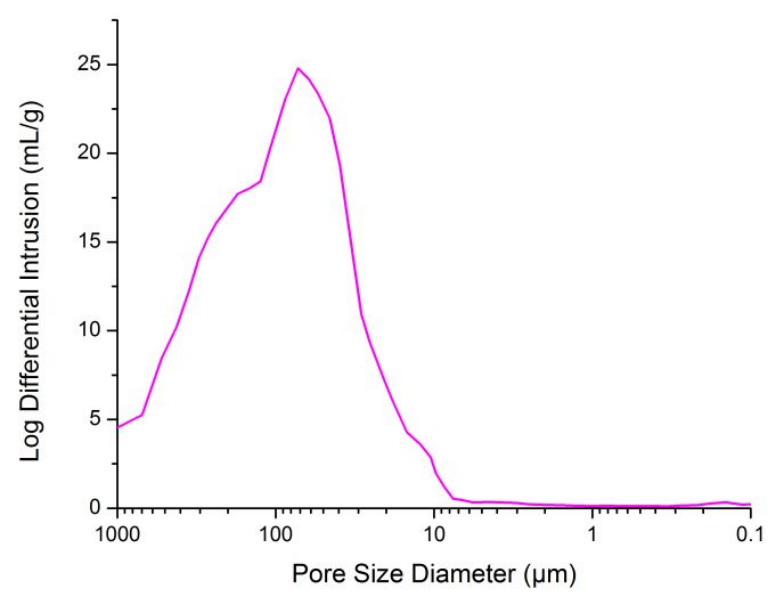

a

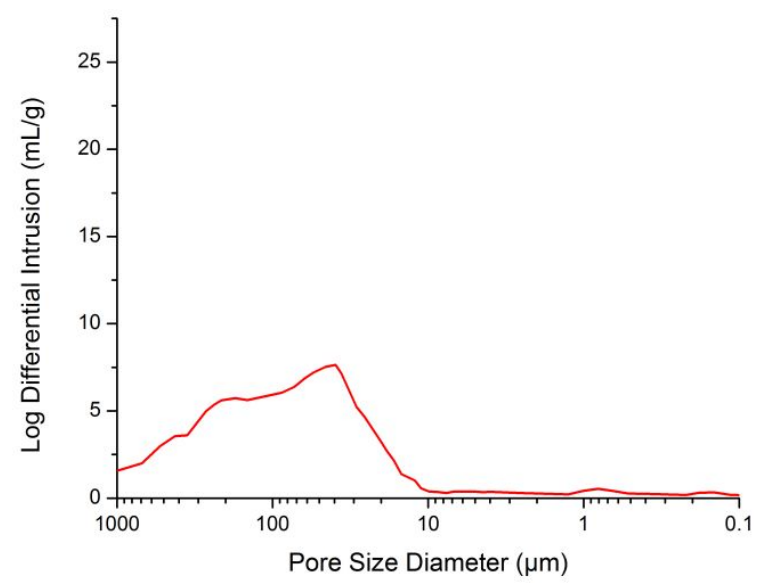

b

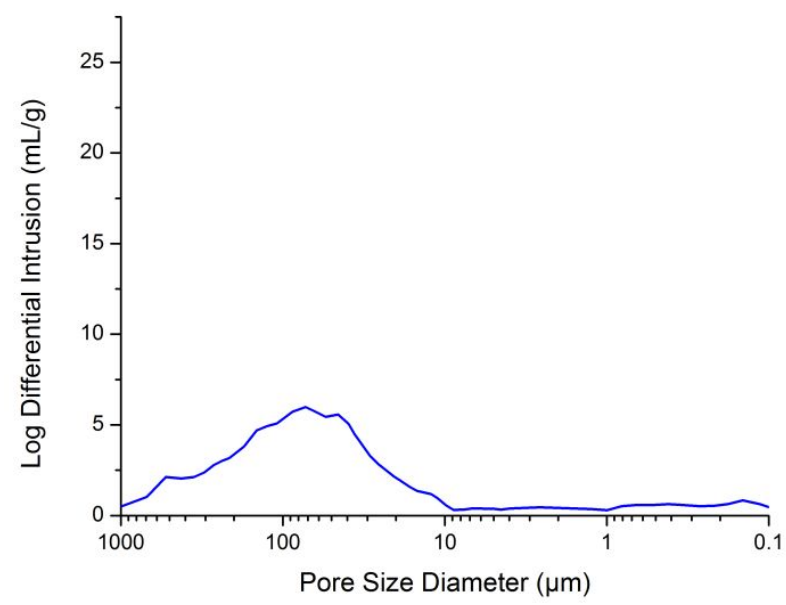

Figure S1. Pore size distributions of (a) nanochitin aerogel, (b) silica-decorated nanochitin aerogel and (c) SNCAs. 


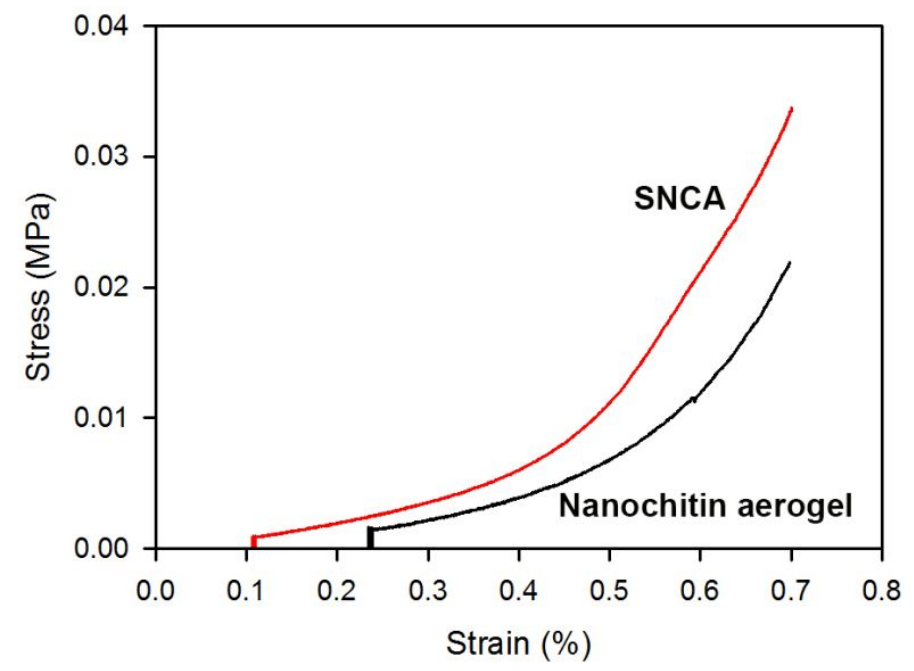

Figure S2. The compressive strength of SNCA and nanochitin aerogels 